\title{
Preparation and Characterization of Activated Carbon from Palm Tree Leaves Impregnated with Zinc Chloride for the Removal of Lead (II) from Aqueous Solutions
}

\author{
Mutasim H. Elhussien ${ }^{1, ~ *, ~ R a s h i d a ~ M . ~ H u s s e i n ~}{ }^{2}$, Sumia A. Nimir ${ }^{1}$, Mawia H. Elsaim ${ }^{3}$ \\ ${ }^{1}$ Department of Chemistry, Faculty of Education, Nile Valley University, Atbara, Sudan \\ ${ }^{2}$ Department of Chemistry, Inaya Medical College, Riyadh, Kingdom of Saudi Arabia \\ ${ }^{3}$ Department of Chemistry, Faculty of Science and Technology, Abdulatif Alhamed University of Technology, Merowe, Sudan
}

Email address:

mutasim1966@yahoo.com (M. H. Elhussien)

${ }^{*}$ Corresponding author

\section{To cite this article:}

Mutasim H. Elhussien, Rashida M. Hussein, Sumia A. Nimir, Mawia H. Elsaim. Preparation and Characterization of Activated Carbon from Palm Tree Leaves Impregnated with Zinc Chloride for the Removal of Lead (II) from Aqueous Solutions. American Journal of Physical Chemistry. Vol. 6, No. 4, 2017, pp. 59-69. doi: 10.11648/j.ajpc.20170604.12

Received: June 27, 2017; Accepted: July 10, 2017; Published: July 31, 2017

\begin{abstract}
Removal of Lead (II) from aqueous solution onto Activated carbon derived from Palm tree leaves (Phoenix dactylifera) as a novel precursor by chemical activation with $\mathrm{ZnCl}_{2}$, at specific condition of carbonization temperature at $500^{\circ} \mathrm{C}$ and 1 hour as a holding time and detonated as $\mathrm{AC}(\mathrm{PTL}) \mathrm{ZnCl}_{2}$. The obtained material was submitted to measurements of active surface area, Fourier Transform Infrared Spectroscopy (FTIR) analysis and scanning electron microscope (SEM). Batchadsorption studied had been carried out to examine the adsorption capacity of the $\mathrm{AC}(\mathrm{PTL}) \mathrm{ZnCl}_{2}$ for the removal of Lead (II) from aqueous solution. The effect of various process parameters like $\mathrm{pH}$, initial metal concentration, adsorbent dose, contact time, and temperature on the efficiency of $\mathrm{Pb}$ (II) removal was investigated. Maximum adsorption of $\mathrm{Pb}$ (II) on $\mathrm{AC}(\mathrm{PTL}) \mathrm{ZnCl}_{2}(86.4 \%)$ was observed at $\mathrm{pH}$ 5.81. The optimum conditions for adsorbent dose and temperature were determined as $0.030 \mathrm{~g}$ and $25^{\circ} \mathrm{C}$, respectively. Initial $\mathrm{Pb}$ (II) concentrations has important effect on $\mathrm{AC}(\mathrm{PTL}) \mathrm{ZnCl}_{2}$ in the studied range $(25-125 \mathrm{mg} / \mathrm{L})$ where the removal percentage increases as the metal ion decrease. The highest percentage removal of concentration corresponding to the maximum adsorption was found to be $82.75 \pm 3.65$. The adsorption equilibrium data was well explained by Langmuir, Freundlich and Dubinin-Radushkevich isotherm. The parameters suggested that the adsorption of $\mathrm{Pb}$ (II) on prepared $\mathrm{AC}(\mathrm{PTL}) \mathrm{ZnCl}_{2}$ is physical adsorption. The Langmuir isotherm which fitted best for the experimental data obtained showed (Correlation Coefficient, $\mathrm{R}^{2}=0.9463$ ) higher than the (Freundlich isotherm, $\mathrm{R}^{2}=0.7554$ ), but more close to (Dubinin-Radushkevich isotherm, $\mathrm{R}^{2}=0.9260$ ). The porous characteristics and adsorption efficiencies of prepared $\mathrm{AC}(\mathrm{PTL}) \mathrm{ZnCl}_{2}$ were also investigated.
\end{abstract}

Keywords: Adsorption Isotherms, Activated Carbon, Palm Tree Leaves, Lead (II), Surface Area, Pore Size, SEM, FTIR

\section{Introduction}

The lack of clean drinking water and rise in environmental water pollution are a growing global concern. So availability of safe drinking water is still distance dream to many around the world, especially in developing countries. Increasing of human activities and industrialization have led to a wide range of physical, chemical and biological pollutants entering water, bodies and affecting human lives, thousands of chemicals have been identified in drinking water supplies around the world hazardous to human health.

Nowadays water pollution by heavy metals is fast growing due to natural processes and increasing human activities which include mining, agriculture, and manufacturing industries [1]. There for, must be work to create a healthier, safer, and cleaner environment for everyone by helping to guarantee clean drinking water, preserving raw water sources and ensuring the optimal operation water purification processes. Heavy metals which 
are natural components of the Earth's crust are usually associated with toxicity. Exposure to heavy metals, even at trace level, is known to be a risk for human beings [2]. There are 59 elements classified as heavy metals and out of these five are considered to be highly toxic and hazardous heavy metals [3]. These are lead $(\mathrm{Pb})$ cadmium $(\mathrm{Cd})$, chromium $(\mathrm{Cr})$, copper $(\mathrm{Cu})$, and zinc $(\mathrm{Zn})$, have a potentially damaging effect on human physiology. Metal toxicity can result from drinking-water contamination (e.g. lead pipes), increased ambient air concentrations near sources of emission, or ingestion via the food chain [4]. The increased use of heavy metals in industry has resulted in increased availability of metallic substances in natural water sources $[5,6]$.

Lead, $\mathrm{Pb}$ (II) is among those contaminants that must be removed from water, due to its high toxicity and tendency to accumulate in tissues of living organisms [7]. Lead can occur in different forms such as organic and inorganic forms. Lead is the most significant toxin of the trace metal ions, and human exposure to the inorganic forms is through ingestion of food and water. As the result, there has been a great deal of attention given to new technologies for removal of heavy metal ions from contaminated water. Many technologies like adsorption, precipitation, membrane filtration, and ion-exchange have been used to remove metal pollutants from water [8]. However, adsorption has proven to be economical and efficient for removing heavy metals, organic pollutants and dyes from polluted waters [9].

Numerous researchers have extensively studied the preparation of activated carbon from various types of precursors and evaluate the performance of such developed materials by adsorbing of different heavy researches have been accomplished on converting low cost raw materials and agricultural waste to activated carbon and evaluate their performance by removing different heavy metal ions. Prepared activated carbon from low cost biosorbent was use to remove several metal ions [10], and A wide variety of activated carbons have been prepared from agricultural waste such as coconut shells, cotton stalk, sugarcane bagasse, coir pith, straw [11-13] and also from nonrenewable materials like coal, wood, peat [14], and many others.

The present study is mainly focused on preparing the micro-porous activated carbon from palm tree leaves (as novel material) by chemical activation method using Zinc Chloride $\left(\mathrm{ZnCl}_{2}\right)$ as a chemical agent. Also, evaluated the removal efficiency of $\mathrm{Pb}$ (II) ions from the aqueous phase using the prepared activated carbon.

\section{Materials and Methods}

The carbonaceous precursor used for preparation of activated carbon (AC) was Palm tree leaves, collected from Alsalam Park in Riyadh, Kingdom of Saudi Arabia. Prior to use, sample was washed gently with water to remove impurities present on the surface and then dried for one week. All chemical reagents used in this work are procured from Pharmchem Haryana and General Drug House (p) Ltd Daryagani, New Delhi, (India).

\subsection{Preparation of Activated Carbon}

Palm tree leave, collected, dried, crushed and grinded in a ball mill. The grinded sample was sieved to obtain the particles of uniform size, $1.0-1.5 \mathrm{~mm}$. The precursor obtained was washed to remove surface bounded impurities and dried at $105^{\circ} \mathrm{C}$ for $24 \mathrm{~h}$. Raw material of about $100 \mathrm{~g}$ was impregnated with $\mathrm{ZnCl}_{2}$ for $24 \mathrm{~h}$ in impregnation ratio of 1: 1.5 at $50{ }^{\circ} \mathrm{C}$ to achieve well penetration of the chemical into the interior of the precursor.

About $10 \mathrm{~g}$ of the Palm tree leave impregnated with the activating agent $\mathrm{ZnCl}_{2}$ and the impregnation was transferred to a stain less steel reactor (150 mm length and $40 \mathrm{~mm}$ diameter) with narrow ports at both ends. The tube is placed inside an electric horizontal tubular furnace (Bysakh \& Co) controlled by the proportional integral derivative (PID) controller. The furnace tube dimensions are $800 \mathrm{~mm}$ length and $50 \mathrm{~mm}$ in diameter. The temperature $\left(500^{\circ} \mathrm{C}\right)$ of the reaction zone was measured by the chromel - alumel (Ktype) thermocouple. The pyrolysis of the samples was carried out under continuous flow of $\mathrm{N}_{2}$ gas $(200 \mathrm{ml} / \mathrm{min})$. The carbonized samples were cooled to room temperature under inert atmosphere and washed with water followed by $0.1 \mathrm{M}$ hydrochloric acid $(\mathrm{HCl})$ to remove the residual chemical agents until the $\mathrm{pH}$ value of the rinsed water was neutral. The adsorbents prepared was denoted as $\mathrm{AC}(\mathrm{PTL}) \mathrm{ZnCl}_{2}$ throughout the work.

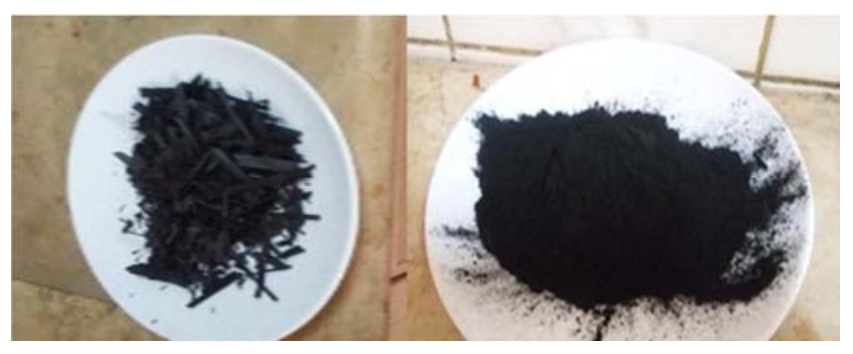

Figure 1. Images of activated carbon obtained from palm tree leave after carbonization process.

\subsection{Evaluation of Activated Carbon}

The activated carbon sample was evaluated three ways:

\subsubsection{Specific Surface Area Measured by Liquid Nitrogen Adsorption}

Nitrogen $\left(\mathrm{N}_{2}\right)$ gas adsorption-desorption isotherms on prepared $\mathrm{AC}(\mathrm{PTL}) \mathrm{ZnCl}_{2}$ at liquid nitrogen temperature ($\left.195.6^{\circ} \mathrm{C}\right)$ were carried out using an automatic adsorption unit, Autosorb - 1(Quanta chrome). The samples were degassed at $200^{\circ} \mathrm{C}$ for $3 \mathrm{~h}$ prior to analysis so as to remove any adsorbed moisture or other impurities bounded to the surface of the sample. Surface area (ST) values were calculated from the experimental adsorption isotherm over a relative pressure range of 0.01 to 0.3 using the standard BET (Brunauer, Emmett and Teller) method. The accuracy of 
measurements performed by this equipment was $\pm 5 \%$. The BET equation is given as [15].

$$
\mathrm{P} / \mathrm{V}\left(\mathrm{P}^{\mathrm{O}}-\mathrm{P}\right)=\left(1 / \mathrm{V}_{\mathrm{m}} \mathrm{C}\right)+(\mathrm{C}-1) \mathrm{P} / \mathrm{P}_{\mathrm{O}} \mathrm{V}_{\mathrm{m}} \mathrm{C}
$$

where, $V$ is the volume adsorbed at STP $\left(\mathrm{cm}^{3} \mathrm{~g}^{-1}\right), V_{m}$ is the volume of monolayer capacity at $\operatorname{STP}\left(\mathrm{cm}^{3} \mathrm{~g}^{-1}\right)$, and the term $C$, the BET constant, is related to the energy of adsorption in the first adsorbed layer and its value is an indication of the magnitude of the adsorbent-adsorbate interactions. The total pore volume $\left(V_{\mathrm{T}}\right)$ of the samples was determined as the total volume of $\mathrm{N}_{2}$ gas adsorbed at high relative pressure (0.995) [16].

\subsubsection{Fourier Transform Infrared Spectroscopy}

The surface functional groups of the ACs were estimated by Fourier Transform Infrared (FTIR) spectroscopy (Nicolet 6700, Thermo Sciatic, USA). FTIR spectra of the activated and inactivated $\mathrm{AC}(\mathrm{PTL}) \mathrm{ZnCl}_{2}$ samples were recorded within $400-4000 \mathrm{~cm}-1$. The transmission spectra of the samples were recorded using the $\mathrm{KBr}$ pellet. About $1.0-2.0 \%$ of the sample was mixed with dry $\mathrm{KBr}$ and grinded in mortar. Then the samples were transferred to hydraulic press. The pellets which are homogeneous and transparent in appearance were dried overnight at $100^{\circ} \mathrm{C}$, and then inserted into the IR sample holder for the analysis.

\subsubsection{Scanning Electron Microscopy (SEM)}

SEM analysis of samples was performed by using (JSM6380LA) scanning electron microscope. The SEM instrument was operated at $5 \mathrm{kV} / \mathrm{SE}$ (Accelerating Voltage Machine), and $50^{\circ} \mathrm{C}$ inclination. Before analysis, all samples were ground and coated in a sputter coating unit (Edwards Vacuum Components Ltd., Sussex, England) to reduce charging and improve the secondary electron signals for imaging. The micrographs were recorded using photographic techniques.

\subsection{Effect of Process Parameters}

Batch adsorption experiments for adsorption of $\mathrm{Pb}$ (II) on $\mathrm{AC}(\mathrm{PTL}) \mathrm{ZnCl}_{2}$ were conducted using aqueous solutions of the metal. A stock solution of $1000 \mathrm{mg} / \mathrm{L}$ of $\mathrm{Pb}$ (II) was prepared by dissolving appropriate weight of $\mathrm{Pb}$ $\left(\mathrm{NO}_{3}\right)_{2}($ General Drug House(p)Ltd. Daryagani, New Delhi (India) in $1 \%(\mathrm{v} / \mathrm{v})$ nitric acid solution in a $1.0 \mathrm{~L}$ volumetric flask. The stock solution was diluted as required to obtain different concentrations of $\mathrm{Pb}$ (II) solutions. For each run, a definite amount of $\mathrm{AC}(\mathrm{PTL}) \mathrm{ZnCl}_{2}$ was added to $25 \mathrm{ml}$ of $\mathrm{Pb}$ (II) solution taken in $100 \mathrm{ml}$ Erlenmeyer flasks. All the adsorption experiments were carried out at constant temperature of $25^{\circ} \mathrm{C}$.

\subsubsection{Effect of $\mathrm{pH}$}

The effect of $\mathrm{pH}$ on metal adsorption was monitored over a $\mathrm{pH}$ range of 1.5 to 9 , using electronic $\mathrm{pH}-\operatorname{Meter}(\mathrm{pH} 211)$. In this study, $25 \mathrm{ml}$ of separate solutions $25 \mathrm{mg} / \mathrm{L} \mathrm{Pb}$ (II) was transferred into $100 \mathrm{ml}$ conical flasks agitated at $100 \mathrm{rpm}$ for
180 min with $0.03 \mathrm{~g} \mathrm{AC(PTL)} \mathrm{ZnCl}_{2}$ at 25 . The mixture was filtered and the filtrate analyzed for residual metal ions using FAAS (model 932AB).

\subsubsection{Effect of Contact Time}

The investigation was done to determine the optimum time for adsorption of lead ions using $\mathrm{AC}(\mathrm{PTL}) \mathrm{ZnCl}_{2}$. The biosorbent $(0.03 \mathrm{~g})$ was contacted with $25 \mathrm{ml}$ separate solutions of $25 \mathrm{mg} / \mathrm{L} \mathrm{Pb}$ (II) ions adjusted to $\mathrm{pH} \mathrm{5.81.} \mathrm{The}$ solution was agitated at $100 \mathrm{rpm}$ for different contact times (1-1440 $\mathrm{min})$ at $25^{\circ} \mathrm{C}$. The mixtures were filtered and residual metal ions in filtrate analyzed using FAAS.

\subsubsection{Effect of Adsorbent Dosage}

The effect of quantity of $\mathrm{AC}(\mathrm{PTL}) \mathrm{ZnCl}_{2}$ used was investigated by equilibrating $25 \mathrm{ml}$ solutions of $25 \mathrm{mg} / \mathrm{L} \mathrm{Pb}$ (II) ions adjusted to $\mathrm{pH} 5.81$, with different masses of the adsorbent (0.01-0.05 g) agitated at $100 \mathrm{rpm}$ for $180 \mathrm{~min}$ at 25 . The mixture was filtered and the residual metal ions in filtrate analyzed using FAAS.

\subsubsection{Effect of Initial Metal Concentration}

Separate $25 \mathrm{ml}$ solution of lead ions with different initial concentrations $(25-125 \mathrm{mg} / \mathrm{L})$ were contacted with optimized

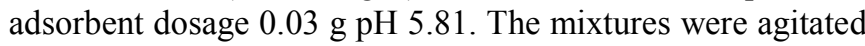
at $100 \mathrm{rpm}$ for $180 \mathrm{~min}$ at $25^{\circ} \mathrm{C}$. The mixtures were filtered and filtrate analyzed for residual metal ions.

\subsubsection{Effect of Temperature}

The effect of temperature of $25 \mathrm{ml}$ solutions, $25 \mathrm{mg} / \mathrm{L} \mathrm{Pb}$ (II) ions on adsorption was monitored over a range of 25 to $55^{\circ} \mathrm{C}$. The investigations were carried out at optimized adsorbent dose, contact time, $\mathrm{pH}$, and agitation time. The mixtures were filtered and filtrate analyzed for residual lead ions using FAAS.

\subsection{Equilibrium Adsorption Studies}

The adsorption isotherms for the adsorption of $\mathrm{Pb}$ (II) onto $\mathrm{AC}(\mathrm{PTL}) \mathrm{ZnCl}_{2}$ were investigated by varying the initial $\mathrm{Pb}$ (II)concentration from 25 to $125 \mathrm{mg} / \mathrm{L}$ at optimized adsorbent dose, contact time, $\mathrm{pH}$, temperature, and stirring speed (established after optimization of working parameters). The equilibrium data were investigations using Langmuir, Freundlich, Dubinin - Radushkevich Isotherms models.

The data obtained in the batch modes were used to calculate the equilibrium metal ion adsorptive amounts $(\mathrm{mg} / \mathrm{g})$ were calculated using the following expressions $[17,18]$ :

$$
\begin{gathered}
q_{e}=(V / w)\left(C_{\mathrm{o}}-C_{e}\right) \\
\% \text { Removal }=100\left(C_{\mathrm{o}}-C_{e}\right) / C_{\mathrm{o}}
\end{gathered}
$$

Where $\mathrm{q}_{\mathrm{e}}$ is the amount of the heavy metal ion adsorbed by the $\mathrm{AC}(\mathrm{PTL}) \mathrm{ZnCl}_{2}$ sample in $(\mathrm{mg} / \mathrm{g}), \mathrm{C}_{\mathrm{o}}$ and $\mathrm{C}_{\mathrm{e}}$ are the initial and equilibrium concentrations of the metal ion respectively in $(\mathrm{mg} / \mathrm{L}), \mathrm{V}$ is the volume of the solution treated in $(\mathrm{L})$ and $\mathrm{w}$ is the adsorbent mass of $\left(\mathrm{AC}(\mathrm{PTL}) \mathrm{ZnCl}_{2}\right)$ in $(\mathrm{g})$. 


\section{Results and Discussion}

\subsection{Evaluation of Activated Carbon}

\subsubsection{Specific Surface Area Measured by Liquid Nitrogen Adsorption}

Surface area and pore properties of the prepared $\mathrm{AC}(\mathrm{PTL}) \mathrm{ZnCl}_{2}$ are tabulated in Table 1.Figure $(2 \&$ \& $)$ represents the incremental mesopore volume and Micropore size distribution for the prepared $\mathrm{AC}(\mathrm{PTL}) \mathrm{ZnCl}_{2}$ respectively. BET surface plot for $\mathrm{N}_{2}$ gas adsorption on the activated prepared sample is shown in Figure 4.
Table 1. Surface area and pore properties of the prepared $A C(P T L) \mathrm{ZnCl}_{2}$ based on $\mathrm{N}_{2}$ adsorption isotherms.

\begin{tabular}{ll}
\hline Physical properties of the prepared AC(PTL) $\mathbf{Z n C l}_{\mathbf{2}}$ \\
\hline BET Surface Area & $299.8424 \pm 5.0495 \% \mathrm{~m}^{2} / \mathrm{g}$ \\
Langmuir Surface Area & $370.8677 \mathrm{~m}^{2} / \mathrm{g}$ \\
$\mathrm{q}_{\mathrm{m}}$ (at STP) & $68.8786 \mathrm{~m}^{3} / \mathrm{g}$ \\
Pore volume & $0.129132 \mathrm{~cm}^{3} / \mathrm{g}$ \\
Pore Size (Adsorption average pore width) & $17.2267 \AA$ \\
Correlation Coefficient, (R) & 0.999585 \\
\hline
\end{tabular}

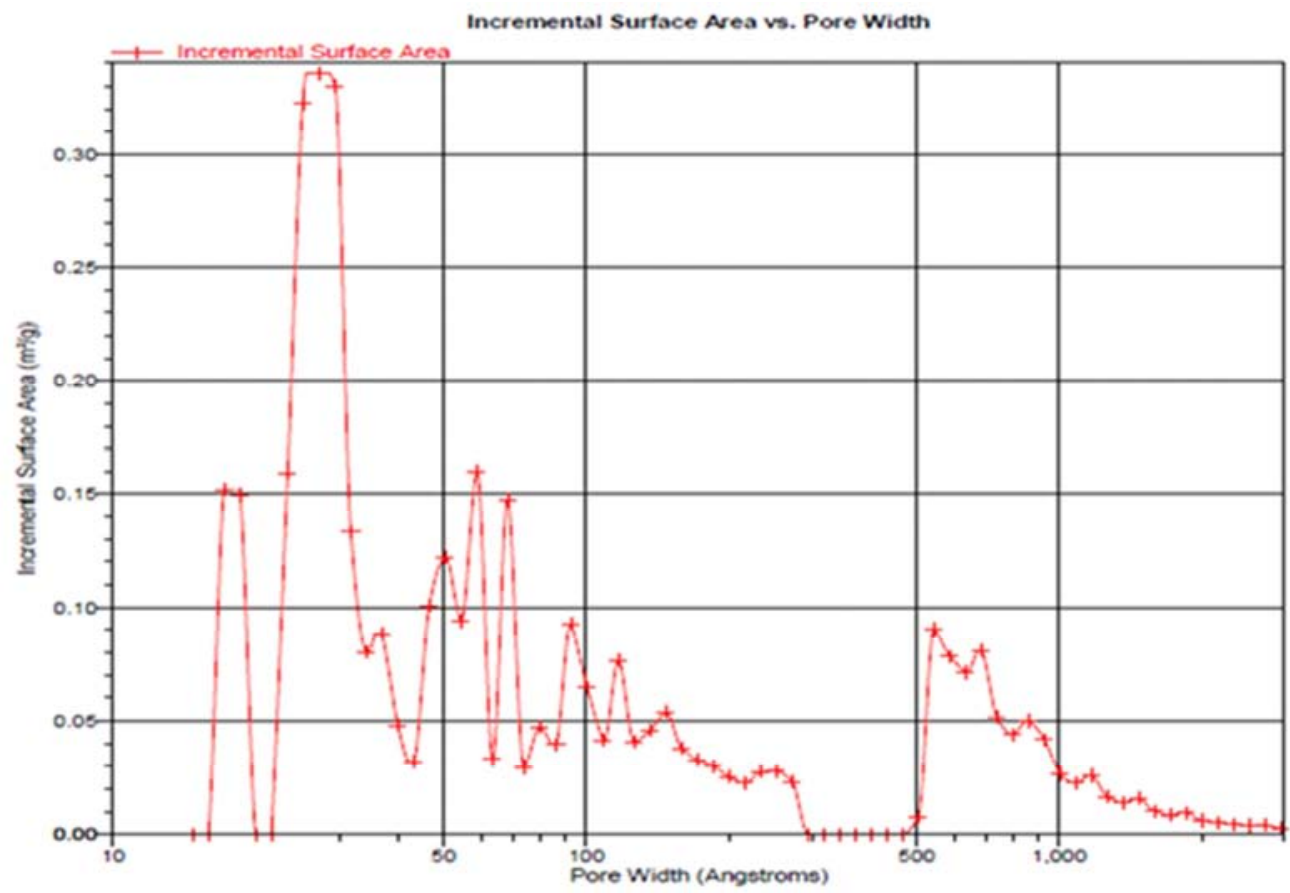

Figure 2. Incremental mesopore volume for prepared $\mathrm{AC}(\mathrm{PTL}) \mathrm{ZnCl}_{2}$

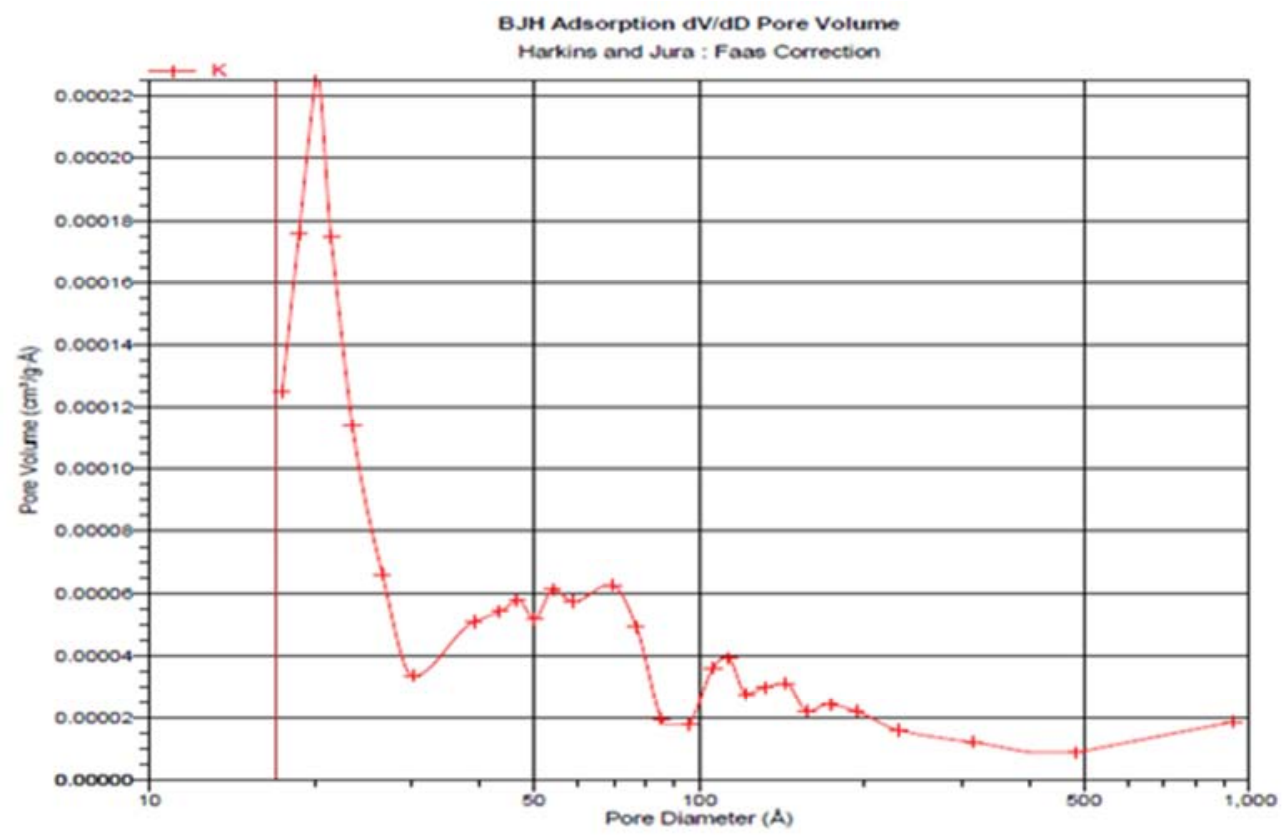

Figure 3. Micropore size distribution for $\mathrm{AC}(\mathrm{PTL}) \mathrm{ZnCl}_{2}$ 


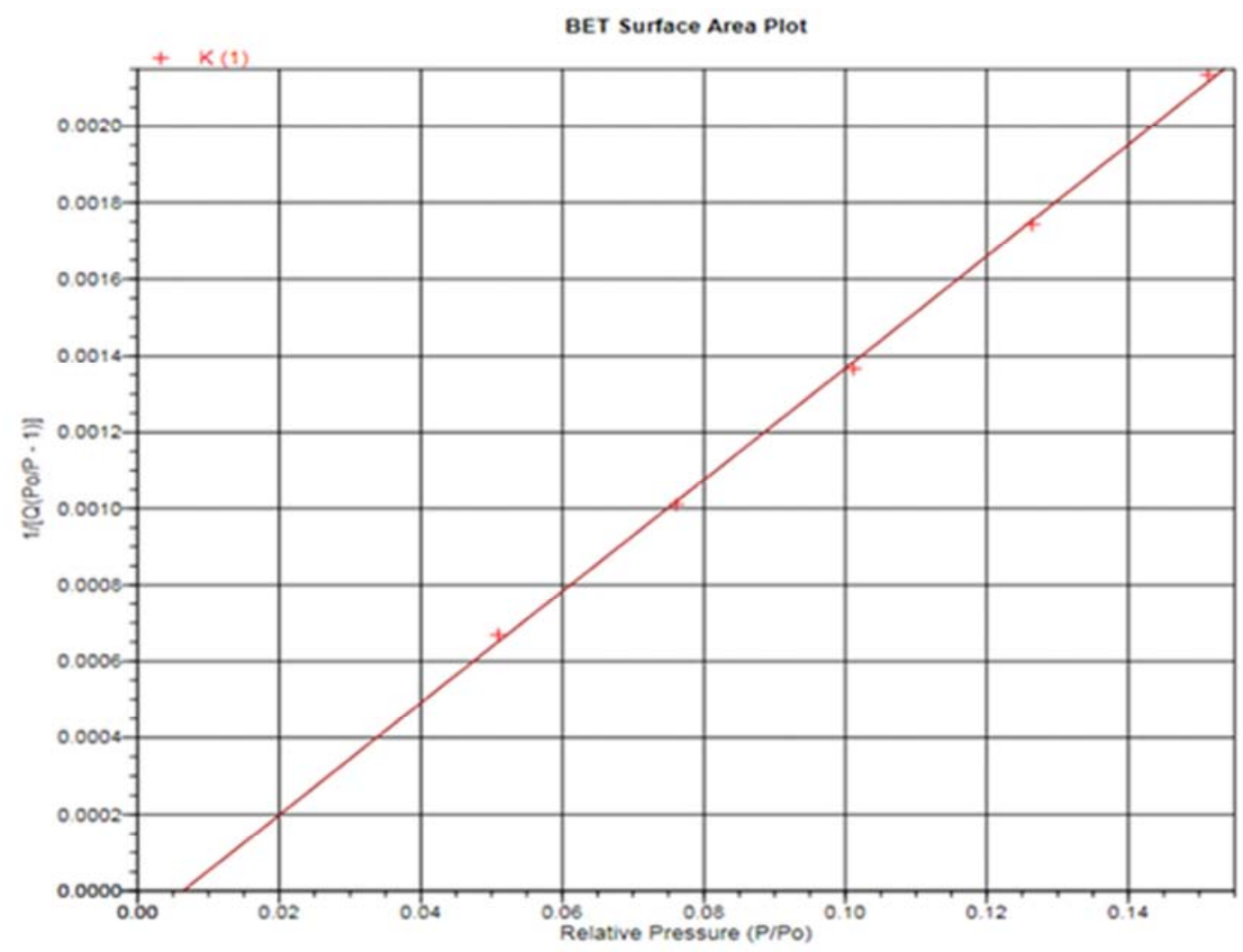

Figure 4. BET plot for $\mathrm{N}_{2}$ gas adsorption on the activated prepared sample.

\subsubsection{Fourier Transform Infrared Spectroscopy (FTIR)}

The FTIR analysis of prepared AC(PTL) $\mathrm{ZnCl}_{2}$ reveals a simple spectrum, shown on figure 5 . The broad peaks at around $3423.43 \mathrm{~cm}^{-1}$ is assigned to presence of $\mathrm{OH}$ groups (adsorbed moisture) on surface. Silane $(\mathrm{Si}-\mathrm{H})$ groups in prepared $\mathrm{AC}(\mathrm{PTL}) \mathrm{ZnCl}_{2}$ were confirmed by the peak at around 2368.66 and $2368.74 \mathrm{~cm}^{-1}$ respectively. A little shift of the bands corresponding to silane groups was observed in prepared ACs. The presence of amine groups are confirmed by the peaks observed at 1612.39 and $1570.40 \mathrm{~cm}^{-1}$ while the band at $1108.13 \mathrm{~cm}^{-1}$ is due to the $\mathrm{C}-\mathrm{N}$ stretching.

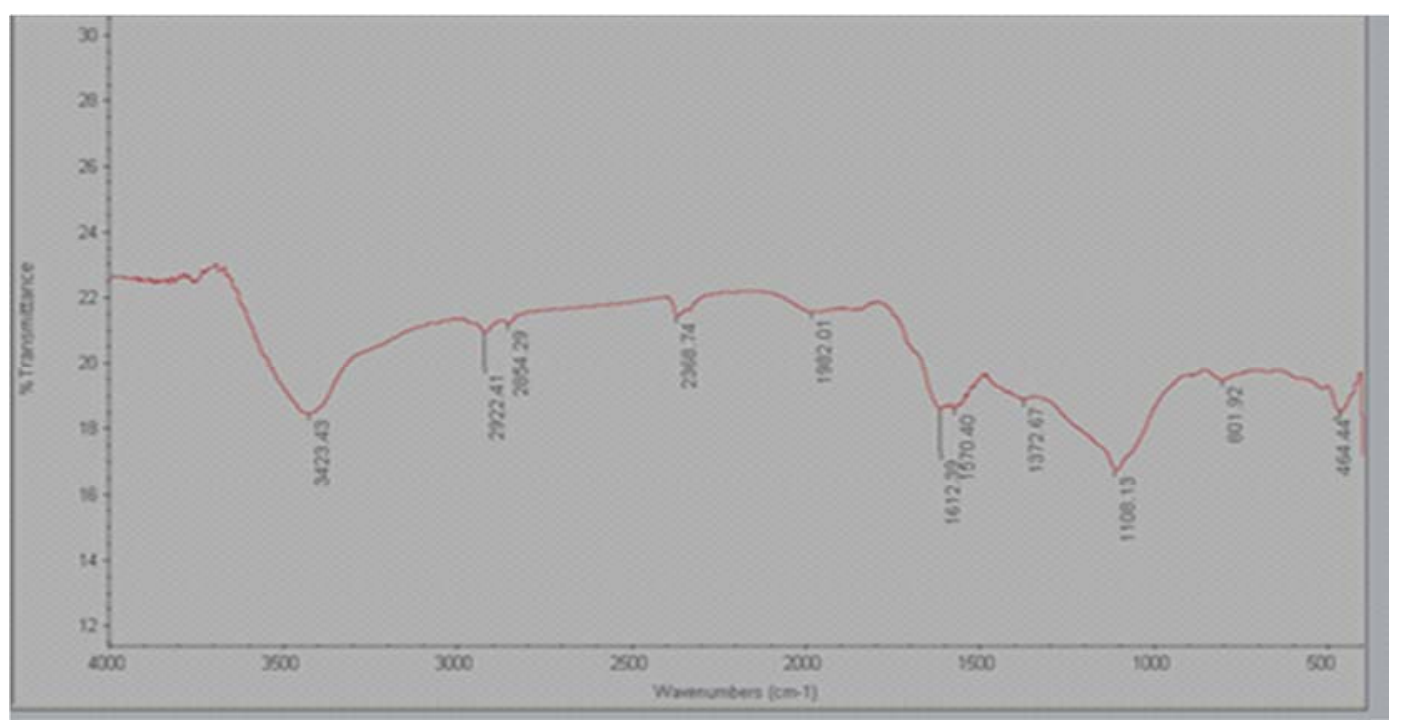

Figure 5. FTIR spectrum of prepared $A C(P T L) Z_{n} C l_{2}$.

\subsubsection{Scanning Electron Microscope (SEM)}

The prepared activated carbon $\mathrm{AC}(\mathrm{PTL}) \mathrm{ZnCl}_{2}$ was examined by Scanning Electron Microscope (SEM) to analyze the surface of the adsorbents. SEM micrographs of the chemically activated carbons by $\mathrm{ZnCl}_{2}$, was presented in Figure 6 respectively. Well-developed porous surface was observed at higher magnification. The pores observed from SEM images are having diameter in micrometer $(\mu \mathrm{m})$ range. 
These pores are considered as channels to the microporous network. From the figure, it can be observed that all the adsorbents have rough texture with heterogeneous surface and a variety of randomly distributed pore size.

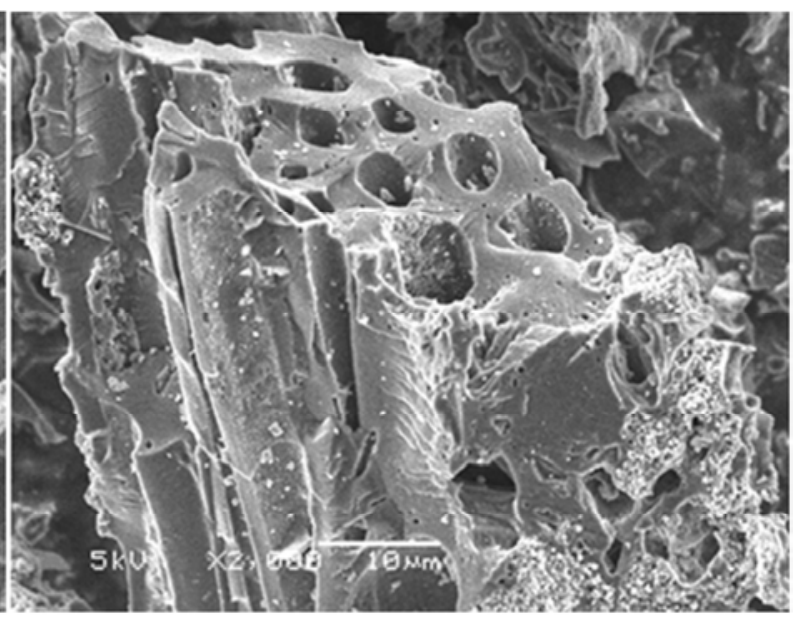

Figure 6. SEM images of the prepared $A C(P T L) \mathrm{ZnCl}_{2}$, Magnification X3000, and X2000.

\subsection{Effect of Process Parameters}

\subsubsection{Effect of $\mathrm{pH}$}

Solution $\mathrm{pH}$ is one of the important process parameters that significantly influences the adsorption of $\mathrm{Pb}$ (II) on adsorbent $[19,20]$. AC(PTL) $\mathrm{ZnCl}_{2}$ was employed for $\mathrm{Pb}$ (II) removal at different $\mathrm{pH}$ values $(1.5-9.0)$. The preliminary experiments were performed at definite experimental conditions (initial $\mathrm{Pb}$ (II) concentration - $25.0 \mathrm{mg} / \mathrm{L}$, adsorbent dose $-0.030 \mathrm{~g}$, contact time $-3.0 \mathrm{~h}$, and temperature $-25^{\circ} \mathrm{C}$ ). Figure 7 shows the higher removal of $\mathrm{Pb}$ (II) at $5.81 \mathrm{pH}$.

It is evident from the figure that the percentage adsorption is higher at acidic $\mathrm{pH}(5.5-5.81)$, reaching maximum of about $86.4 \% \pm 4.2$. But it decreased gradually with the decrease in $\mathrm{pH}$. The maximum adsorption capacities observed at $\mathrm{pH} 5.81 .0(18.00 \mathrm{mg} / \mathrm{g})$.Adsorption values at $\mathrm{pH}$ greater than 6.9 gives rise to lead precipitation, so that active sites would have achieved saturation above a certain range of $\mathrm{pH}$ values. The results obtained are in close agreement with reported studies $[19,21]$.

These obtained results could be explained as, in acidic media i.e. when the $\mathrm{pH}$ of solution less than 4 , the elevated hydrogen ions $\left(\mathrm{H}^{+}\right)$will rival the $\mathrm{Pb}$ (II) ions from reaching the free available sites on the adsorbent surface and prevent the $\mathrm{Pb}$ (II) ions from bounding with activated carbon surface due to the repulsive forces. Besides that, it is also noted when the $\mathrm{pH}$ values reaches 5.81, the adsorption process enhanced and removal percentage get maximum quantities regarding the lower hydrogen ions $\left(\mathrm{H}^{+}\right)$exist, and on the sense the $\mathrm{Pb}$ (II) ions will get better chance to occupy the free sites of the active surface. Later on, when the $\mathrm{pH}$ precede toward basic region and elevated above 5.81, the recorded values of removal ions increase significantly specially at 7 and $9 \mathrm{pH}$ to record higher values. This is attributed to $\mathrm{Pb}$ (II) ions precipitated regarding to the formation of lead hydroxide anions due to the dissolution of $\mathrm{Pb}(\mathrm{OH})_{2}$ as a result $[18,21]$.

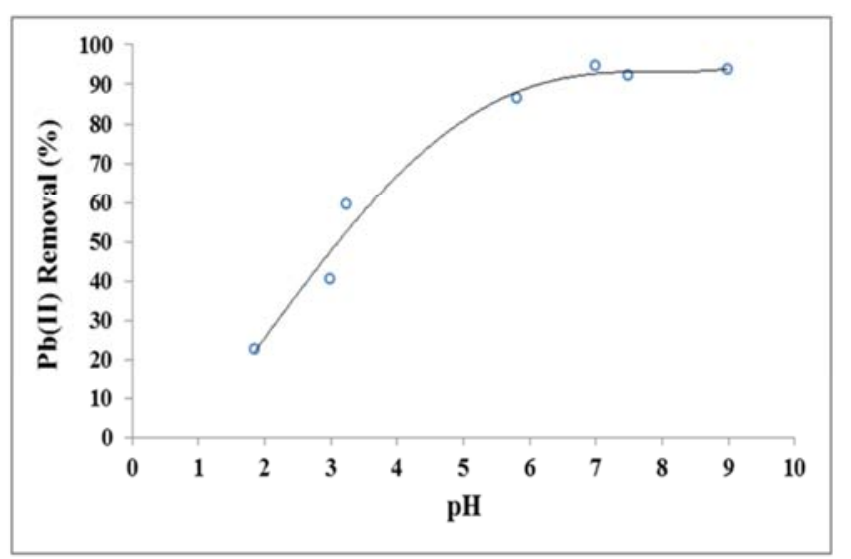

Figure 7.Effect of $\mathrm{pH}$ on $\mathrm{Pb}$ (II) removal by $\mathrm{AC}(\mathrm{PTL}) \mathrm{ZnCl}_{2}$ (Initial concentration - $25 \mathrm{mg} / \mathrm{L}$, adsorbent dose - $0.030 \mathrm{~g}$, Agitation speed - 100 rpm, contact time $-3.0 \mathrm{~h}$, and temperature $-25^{\circ} \mathrm{C}$ ).

\subsubsection{Effect of Adsorbent Dose}

The effect of adsorbent dose on removal percentage of $\mathrm{Pb}$ (II) using $\mathrm{AC}(\mathrm{PTL}) \mathrm{ZnCl}_{2}$ was illustrated in Figure8. Different doses of adsorbents ranging from $0.01-0.050 \mathrm{~g}$ were considered and other process parameters were maintained constant $(\mathrm{pH}-5.81 \mathrm{~Pb}$ (II) concentration $-25.0 \mathrm{mg} / \mathrm{L}$, Agitation speed - $100 \mathrm{rpm}$, contact time $-3.0 \mathrm{~h}$, and temperature $-25^{\circ} \mathrm{C}$ ).

An increase in adsorption capacity with increasing adsorbent dose up to a maximum of $0.03 \mathrm{~g}$ giving the corresponding optimum percentage removal of $78.48 \%$. On the other hand, it is found that any further addition over the above mentioned weight $(0.03 \mathrm{~g})$ will not make any enhancement in the adsorption process, where almost negligible increase of removal efficiency over the specific adsorbent dose. The initial increase in adsorption capacity with increasing adsorbent mass is explained by the increase in the number of exchangeable sites for metal ion adsorption, after which equilibration was attained $[18,22]$. 


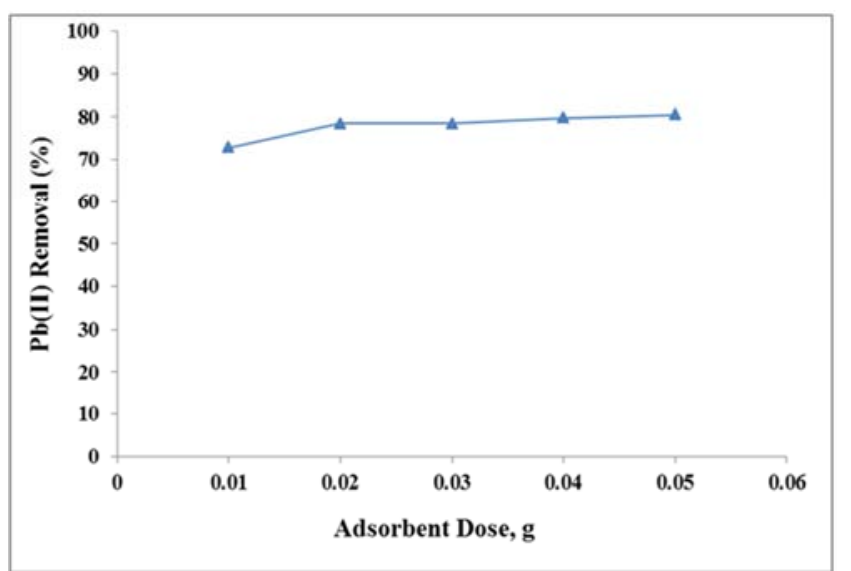

Figure 8. Effect of adsorbent dose on Pb (II)removal by $\mathrm{AC}(\mathrm{PTL}) \mathrm{ZnCl}_{2}$ ( $(p H-5.81$ Initialconcentration $-25 \mathrm{mg} / \mathrm{L}$, Agitation speed - $100 \mathrm{rpm}$, contact time $-3.0 \mathrm{~h}$, and temperature $-25^{\circ} \mathrm{C}$ ).

\subsubsection{Effect of Contact Time}

The effect of contact time on the removal of lead (II) is shown in Figure 9. The amount of the adsorbed metal ions increases with increasing time until it levels off after some (180 min). A constant adsorption is indicative of equilibration due to saturation of adsorption sites. Rapid adsorption of metal ions during the initial stages was due to the large initial concentration gradient between the adsorbate in solution and the number of available vacant sites on the adsorbent surface $[18,19,23]$.

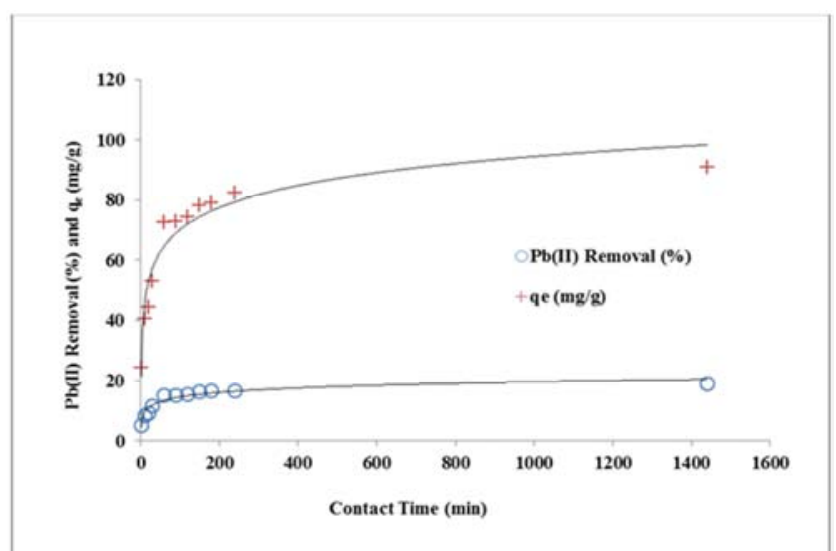

Figure 9. Effect of contact time on $\mathrm{Pb}$ (II) removal by $\mathrm{AC}(\mathrm{PTL}) \mathrm{ZnCl}_{2}((\mathrm{pH}-$ 5.81 , Initial concentration $-25 \mathrm{mg} / \mathrm{L}$, adsorbent dose - $0.030 \mathrm{~g}$, Agitation speed $-100 \mathrm{rpm}$, and temperature $-25^{\circ} \mathrm{C}$ ).

\subsubsection{Effect of Initial Lead (II) Concentration}

The initial concentration of metal ions in the solution is an important parameter since the metal ions concentration change over a broad range in effluents applications.

The batch adsorption experiments were carried out with different initial concentrations $\left(C_{i}\right)(25,50,75,100$, and 125). The variation of percentage removal of $\mathrm{Pb}$ (II) ions with different initial concentration for the prepared activated carbon $\mathrm{AC}(\mathrm{PTL}) \mathrm{ZnCl}_{2}$ was clarified in Figure 10.The figure shows a excellent performance of the prepared activated carbon at equilibrium state and clarify the optimum $\mathrm{Pb}$ (II) ions initial concentration used at confined experimental conditions.

It is also evidently observed that the percentage removal of the $\mathrm{Pb}$ (II) ions is sufficiently high, $(86.4 \%)$ at low concentration $(25 \mathrm{mg} / \mathrm{L})$ and gradually decreases as the concentration increases [18]. This could be attributed to the fact that after the formation of mono-ionic layer at low concentration over the activated carbon surface, further formation of the layer is highly hindered at higher concentration and is due to interaction between $\mathrm{Pb}$ (II) ions on the surface and in the solution $[18,23]$.

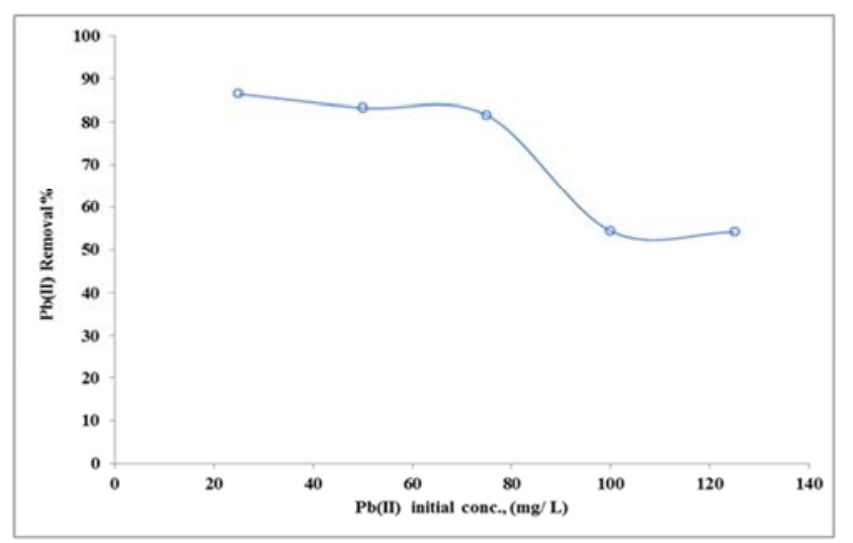

Figure 10. Effect of $\mathrm{Pb}$ (II)initial concentration on it's removal by $A C(P T L) \mathrm{ZnCl}_{2}$ ( $\mathrm{pH}-5.81$, contact time $-3 \mathrm{~h}$, adsorbent dose $-0.030 \mathrm{~g}$, Agitation speed $-100 \mathrm{rpm}$, and temperature $-25^{\circ} \mathrm{C}$ ).

\subsubsection{Effect of Temperature}

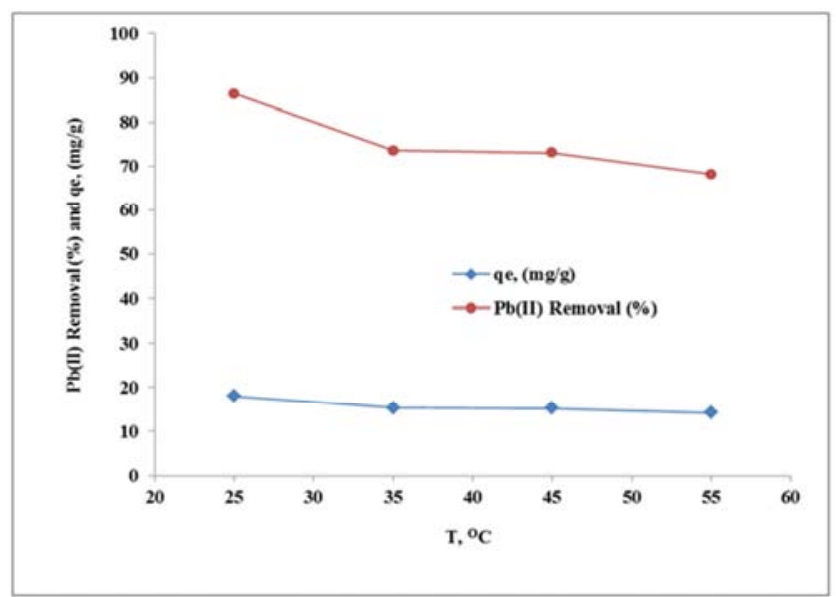

Figure 11. Effect of temperature on $\mathrm{Pb}$ (II) removal and $q_{e}(\mathrm{mg} / \mathrm{g})$ by $A C(P T L) Z n C l_{2}(p H-5.81$, Initial concentration - $25 \mathrm{mg} / \mathrm{L}$, adsorbent dose $0.030 \mathrm{~g}$, Agitation speed $-100 \mathrm{rpm}$, and contact time - $3.0 \mathrm{~h}$ ).

Effect of temperature on $\mathrm{Pb}$ (II) removal percentage on $\mathrm{AC}(\mathrm{PTL}) \mathrm{ZnCl} 2$ was shown in Figure 11. Experiments were performed in the temperature range $25-55^{\circ} \mathrm{C}$ at constant $\mathrm{Pb}$ (II) concentration $(25.0 \mathrm{mg} / \mathrm{L})$, adsorbent dose $(0.030 \mathrm{~g})$, contact time $(3.0 \mathrm{~h})$ and $\mathrm{pH}(5.81)$ for $\mathrm{AC}(\mathrm{PTL}) \mathrm{ZnCl}_{2}$. Adsorption of $\mathrm{Pb}$ (II) on the adsorbent witnessed the increase in removal percentage and adsorption capacity $\left(q_{\mathrm{e}}\right)$ at $25^{\circ} \mathrm{C}$, while in the range from 35 to $55^{\circ} \mathrm{C}$, no significant change with further increase of temperature. The figure represents high rate of adsorption at at 25 . However low 
rate of $\mathrm{Pb}$ (II) adsorption was observed at $55^{\circ} \mathrm{C}$ within studied range of temperatures. The adsorption of $\mathrm{Pb}$ (II) on $\mathrm{AC}(\mathrm{PTL}) \mathrm{ZnCl}_{2}$ decreased from 83.3 to $11.0 \%$, with the rise in temperature from 25 to 55 . This indicates that the removal of $\mathrm{Pb}$ (II)onto $\mathrm{AC}(\mathrm{PTL}) \mathrm{ZnCl}_{2}$ is exothermic [18, $19,24]$.

The high removal percentage of $\mathrm{Pb}$ (II) by $\mathrm{AC}(\mathrm{PTL}) \mathrm{ZnCl}_{2}$ may be due to the high diffusion rate of metal ions into the pores as the surface area and pore volume of the adsorbent were large, However, at high temperature the kinetic energy of $\mathrm{Pb}$ (II)species is low and hence contact between the metal ions and the active sites of $\mathrm{AC}$ is in sufficient, resulting in reduced removal efficiency $[25,26,27]$.

\subsection{Adsorption Isotherms}

The successful representation of the dynamic adsorptive separation of solute from solution by an adsorbent depends upon a good description of the equilibrium between the two phases. Adsorption equilibrium is established when the amount of solute being adsorbed onto the adsorbent is equal to the amount being desorbed [28]. The equilibrium adsorption isotherms were depicted by plotting solid phase concentration $\left(q_{\mathrm{e}}\right)$ against liquid phase concentration $\left(C_{\mathrm{e}}\right)$ of solute.

Adsorption isotherm explains the interaction between adsorbate and adsorbent and is critical for design of adsorption process. The Langmuir, Freundlich, and D-R isotherms are the most frequently used models to describe the experimental data of adsorption. In the present work these four isotherms were applied to investigate the adsorption process of $\mathrm{Pb}$ (II) on prepared $\mathrm{AC}(\mathrm{PTL}) \mathrm{ZnCl}_{2}$ at different conditions of process parameters.

\subsubsection{Langmuir Isotherm}

The Langmuir isotherm is applicable to homogeneous sorption where the sorption of each sorbate molecule on to the surface has equal sorption activation energy and is represented as follows $[29,30]$ :

$$
\mathrm{q}_{\mathrm{e}}=\mathrm{K}_{\mathrm{L}} \mathrm{C}_{\mathrm{e}} /\left(1+\mathrm{a}_{\mathrm{L}} \mathrm{C}_{\mathrm{e}}\right)
$$

Where $\mathrm{q}_{\mathrm{e}}$ is the solid phase sorbate concentration at equilibrium, $K_{L}$ and $\mathrm{a}_{\mathrm{L}}$ are the Langmuir isotherm constants.

The linear form of Langmuir equation is given as:

$$
\mathrm{C}_{\mathrm{e}} / \mathrm{q}_{\mathrm{e}}=1 / \mathrm{K}_{\mathrm{L}}+\left(\mathrm{a}_{\mathrm{L}} / \mathrm{K}_{\mathrm{L}}\right) \mathrm{C}_{\mathrm{e}}
$$

The adsorption data were analyzed according to the linear form of equation (equation 5). The plots of $C_{e} / q_{e}$ versus $C_{e}$ are linear which indicate that the adsorption data fitted reasonably to the Langmuir isotherm (Figure 12). The constants were evaluated from the slope $a_{L} / K_{L}$ and intercept $1 / K_{L}$, where $K_{\mathrm{L}} / a_{\mathrm{L}}$ gives the theoretical monolayer saturation capacity $Q_{0}$. The Langmuir constants obtained are summarized in Table 2.

The positive value of $\mathrm{a}_{\mathrm{L}}$ (0.166), obtained for $\mathrm{AC}(\mathrm{PTL}) \mathrm{ZnCl}_{2}$ indicates the efficiency of Langmuir model to explain the adsorption process. The adsorption data for
$\mathrm{AC}(\mathrm{PTL}) \mathrm{ZnCl}_{2}$ was well fitted to the Langmuir equation with reasonably high regression coefficient (0.9463).

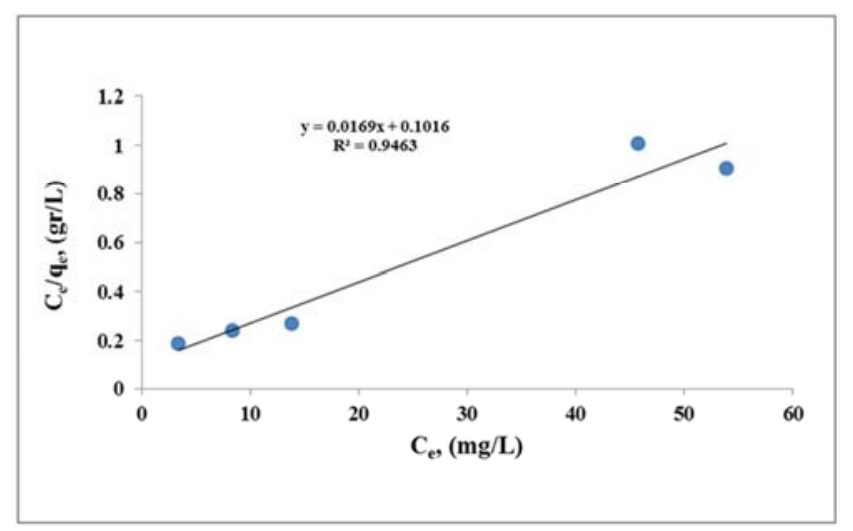

Figure 12. Langmuir isotherms of $A C(P T L) \mathrm{ZnCl}_{2}$ for the $\mathrm{Pb}$ (II) removal at $25^{\circ} \mathrm{C}$.

\subsubsection{Freundlich Isotherm}

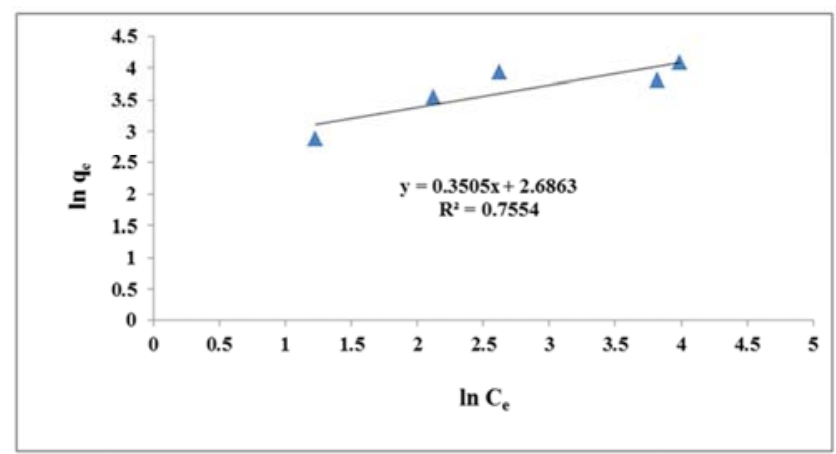

Figure 13. Freundlich isotherms of $A C(P T L) \mathrm{ZnCl}_{2}$ for the $\mathrm{Pb}$ (II) removal at $25^{\circ} \mathrm{C}$.

The most important multilayer adsorption isotherm for heterogeneous surfaces is the Freundlich isotherm which is characterized by the heterogeneity factor $1 / n$, and is represented by the equation:

$$
q_{e}=K_{F} C_{e}^{1 / n}
$$

where, $q_{e}$ is the solid phase concentration in equilibrium, $C_{e}$ is the liquid phase sorbent concentration at equilibrium, $K_{F}$ is the Freundlich constant and $1 / n$ is the heterogeneity factor. The magnitude of $n$ gives an indication on the favorability of adsorption. It is generally stated that the values of $n$ in the range $2-10$ represent good, $1-2$ moderately good, and less than 1 poor adsorption characteristics [31]. The Freundlich isotherm is an empirical equation based on an exponential distribution of adsorption sites and energies. The linear form of Freundlich equation is:

$$
\ln \mathrm{q}_{\mathrm{e}}=\ln \mathrm{K}_{\mathrm{F}}+(1 / \mathrm{n}) \ln \mathrm{C}_{\mathrm{e}}
$$

where, the intercept $\ln K_{\mathrm{F}}$ is a measure of adsorption capacity, and the slope $1 / n$ is the adsorption intensity. The values of $K_{\mathrm{F}}$ and $n$ were calculated from the intercept and slope of the plots $\ln q_{e}$ against $\ln C_{e}$ (Figure 13). The Freundlich isotherm describes reversible adsorption and was 
not restricted to the formation of monolayer. The Freundlich isotherm showed a poor fit to the adsorption data than Langmuir isotherm, with regression coefficient of 0.7554 compared to 0.9463 in Langmuir. This indicates that $\mathrm{Pb}$ (II) adsorption on $\mathrm{AC}(\mathrm{PTL}) \mathrm{ZnCl}_{2}$ was monolayer adsorption. Freundlich sorption isotherm constants were determined and are summarized in Table 2.

\subsubsection{Dubinin - Radushkevich Isotherm}

The linear form of Dubinin - Radushkevich (DR) isotherm equation is presented as [32]:

$$
\ln \mathrm{q}_{\mathrm{e}}=\ln \mathrm{q}_{\mathrm{D}}-2 \mathrm{~B}_{\mathrm{D}} \mathrm{RT} \ln \left(1+1 / \mathrm{C}_{\mathrm{e}}\right)
$$

A plot of $\ln q_{\mathrm{e}}$ against $R T \ln \left(1+1 / C_{\mathrm{e}}\right)$ in Figure 14 showed straight line and indicates a good fit of the isotherm to the experimental data. The apparent energy $(E)$ of adsorption from DR isotherm model can be estimated using the equation given below:

$$
\mathrm{E}=1 /\left(2 \mathrm{~B}_{\mathrm{D}}\right)^{1 / 2}
$$

The DR isotherm constants and mean free energy were presented in Table 2. It was found that the DR isotherm model gives a satisfactory fit for $\mathrm{Pb}$ (II) adsorption data for $\mathrm{AC}(\mathrm{PTL}) \mathrm{ZnCl}_{2}$ with good regression coefficient (0.926). The magnitude of the activation energy can be used to determine the type of adsorption process. It easy to have a general insight into the undergoing process. If the value of $E<8$ $\mathrm{kJ} / \mathrm{mol}$, the adsorption type can be explained by physisorption, and if $E$ is in the range of $8-18 \mathrm{~kJ} / \mathrm{mol}$ then the adsorption type is ion exchange [33], and chemicalreaction-controlled when $E>50 \mathrm{~kJ} / \mathrm{mol}[23,34]$. The low value of apparent energies obtained $(0.09414 \mathrm{~kJ} / \mathrm{mol})$ confirms that the adsorption of $\mathrm{Pb}$ (II) on prepared $\mathrm{AC}(\mathrm{PTL}) \mathrm{ZnCl}_{2}$ is physical adsorption [35].

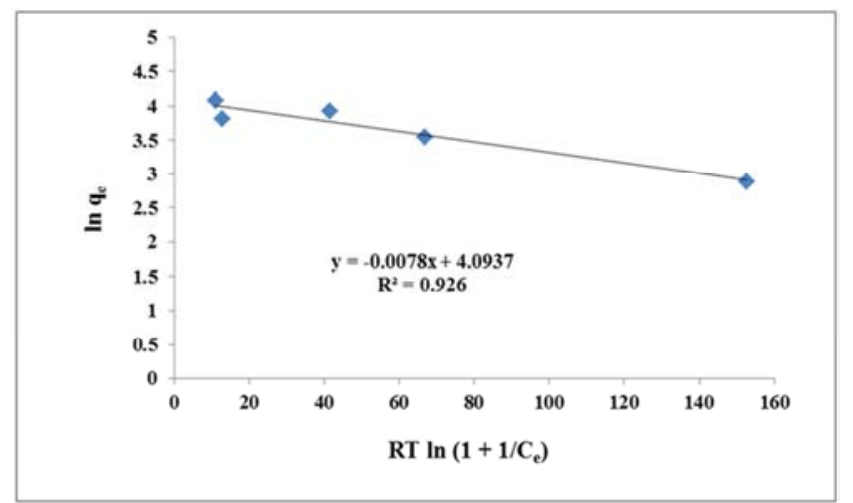

Figure 14. Dubinin - Radushkevich isotherms of $A C(P T L) \mathrm{ZnCl}_{2}$ for the $\mathrm{Pb}$ (II) removal at $25^{\circ} \mathrm{C}$.

\begin{tabular}{|c|c|c|c|c|c|c|c|c|c|c|}
\hline \multicolumn{4}{|c|}{ Langmuir } & \multicolumn{3}{|c|}{ Frenudlich } & \multicolumn{4}{|c|}{ Dubinin Radushkevich } \\
\hline$K_{L}(L / m g)$ & $\mathbf{a}_{\mathrm{L}}(\mathrm{L} / \mathrm{mol})$ & $Q_{0}(\mathrm{mg} / \mathrm{g})$ & $\mathbf{R}^{2}$ & $\begin{array}{c}\mathrm{K}_{\mathrm{f}},[(\mathrm{mg} / \mathrm{g}) \\
\left.(\mathrm{L} / \mathrm{mg})^{1 / \mathbf{n}}\right]\end{array}$ & $1 / n$ & $\mathbf{R}^{2}$ & $\begin{array}{c}\mathrm{B}_{\mathrm{D}} \mathrm{X} 10^{-3} \\
\left(1 /(\mathrm{J} / \mathrm{mol})^{2}\right)\end{array}$ & $q_{D}(m g / g)$ & E (J/mol) & $\mathbf{R}^{2}$ \\
\hline 9.843 & 0.166 & 59.30 & 0.9463 & 0.988 & 0.351 & 0.7554 & 3.9 & 1.41 & 94.14 & 0.926 \\
\hline
\end{tabular}

Table 2. Langmuir, Freundlich, and Dubinin-Radushkevich isotherm constants for the Pb (II) removal on the prepared $A C(P T L) Z n C l_{2}$ at $25^{\circ} \mathrm{C}$.

\section{Conclusion}

The main conclusions which are achieved from this research are:

1. The prepared activated carbon, $\mathrm{AC}(\mathrm{PTL}) \mathrm{ZnCl}_{2}$, used in this study is found to have a high capability for removing the $\mathrm{Pb}$ (II) ions from aqueous solution.

2. The adsorption method is successfully applied to remove $\mathrm{Pb}$ (II) ions from aqueous solution. The removal efficiency of lead (II) ions was found to be dependent on various parameters such as $\mathrm{pH}$ of the solution, initial lead concentration, mass of adsorbent and contact time.

3. The results obtained showed that the removal efficiency of the $\mathrm{Pb}$ (II) ions by the prepared activated carbon, $\mathrm{AC}(\mathrm{PTL}) \mathrm{ZnCl}_{2}$, increased with time, which is significant in the first stage with an instantaneous removal of $\mathrm{Pb}$ (II) ions, after that the curves become as plateau after 180 minutes.

4. The experimental results showed that the removal efficiency of the $\mathrm{Pb}$ (II) ions by $\mathrm{AC}(\mathrm{PTL}) \mathrm{ZnCl}_{2}$ activated carbon decreases with increase in initial $\mathrm{Pb}$ (II) ions concentration, and increases with increase in mass of adsorbent.

5. The $\mathrm{pH}$ of the solution played an important role in influencing the ability of adsorbents towards the metal ion. The increase in the $\mathrm{pH}$ of solution from 2 to 5.81led to increase in the removal efficiency.

6. The optimum conditions which have been obtained in adsorption process for treating the aqueous phase were $50 \mathrm{ppm}$ for initial lead concentration, $5.81 \mathrm{pH}$ for solution acidity, and $15 \mathrm{~g} / \mathrm{L}$ for mass of adsorbent.

7. The equilibrium data obtained for the prepared activated carbon, $\mathrm{AC}(\mathrm{PTL}) \mathrm{ZnCl}_{2}$, is fitted to the Langmuir and Dubinin - Radushkevich models more than the Freundlich model.

\section{Acknowledgements}

We would like to thank Dr. Mohammed Elfaki at Chemistry Department, Faculty of Science, King Saud University, for supporting and assistance to conduct this study.

\section{References}

[1] N. M. Andal, and V. Sakthi, A comparative study on the sorption characteristics of $\mathrm{Pb}$ (II) and $\mathrm{Hg}$ (II) onto activated carbon, Journal of Chemistry, 7(3), 2010, 967-974.

[2] N. A. Babarinde, J. O. Babalola, and A. R. A. Sanni, Biosorption of lead ions from aqueous solutions by maize leaf, International Journal of Physical Sciences, 1(1), 2006, 23-26. 
[3] S. D. Kim, K. S. Park, and M. B. Gu, Toxicity of hexavalent chromium to Daphnia magna: influence of reduction reaction by ferrous iron, Journal of Hazardous Materials, 93(2), 2002, $155-164$.

[4] P. A. Maryan, H. M. Pinheiro, J. A. Teiseira, and M. F. Rosa, Removal efficiency of $\mathrm{Cu}$ (II), $\mathrm{Cd}$ (II) and $\mathrm{Pb}$ (II) by waste brewery biomass, $\mathrm{pH}$ and cation association effects, Desalination Journal, 124, 2007, 137-144.

[5] A. B. Paknikar, A. Ballester, F. Gonzalez, M. L. Blazquez, J. A. Murioz, J. Saez, and M. Zapata, Study of cadmium, zinc and lead biosorption by orange wastes using the subsequent addition method, Bioresources Technology Journal, 99(17), 2003, 8101-8106

[6] J. C. Ingwe, O. F. Mbonu, and A. A. Abia, Sorption Kinetic, Interparticle Diffusion and Equilibrium Partitioning of Azo Dyes on Great Millet (Andropogon Sorghum) Waste Biomass, Journal of Applied Sciences, 7(19), 2007, 2840-2847.

[7] C. L. Ake, K. Mayura, H. Huebner, G. R. Bratton, and T. D. Phillips, Development of porous clay based composites for the sorption of lead from water, Journal of Toxicology Environmental Health Part A 63 (6), 2001, 459-4759.

[8] Z. Asku, Application of biosorption for the removal of organic pollutants: a review, Process Biochemistry, 40, 2009, 99710268 .

[9] M. Lotfi, and N. Adhoum, Modified activated carbon for the removal of copper, zinc, chromium and cyanide from wastewater, Separation and Purification Technology, 26 ( 2 3), 2002, 137-146.

[10] Reddad, Z.; Gerente, C.; Andres, Y. and Pierre, L. C. 2002. Adsorption of several metal ions onto a low cost biosorbent: Kinetic and Equilibrium studies. Environ. Sci. Technol., 36(9), pp: 2067-2073.

[11] Laine, J. and A. Calafat, Preparation and characterization of activated carbons from coconut shell impregnated with phosphoric acid. Carbon. Vol. 27, No. 2, pp. 191-195, 1989.

[12] Girgis, B. S. and M. F. Ishak, Activated carbon from cotton stalks by impregnation with phosphoric acid. MaterialsLetters. Vol. 39, No. 2, pp. 107-114, 1999.

[13] Ahmedna, M., W. E. Marshall, and R. M. Rao, Surface properties of granular activated carbons from agricultural byproducts and their effects on raw sugar decolorization. Bioresource technology. Vol. 71, No. 2, pp. 103-112, 2000.

[14] Kadirvelu, K., M. Kavipriya, C. Karthika, M. Radhika, N. Vennilamani, and S. Pattabhi, Utilization of various agricultural wastes for activated carbon preparation and application for the removal of dyes and metal ions from aqueous solutions. Bioresource technology. Vol. 87, No. 1, pp. 129-132, 2003.

[15] Brunauer, S., Emmet, P. H., Teller, E. Adsorption of gases in multi molecular layers. Journal of American Chemical Society, 60 (2), 1938, 309-319.

[16] Sricharoenchaikul, V., Chiravoot, P., Duangdao, A., Duangduen, A. T. Preparation and characterization of activated carbon from the pyrolysis of physic nut (Jatropha curcas L.) waste, Energy Fuels 22 (2008) 31-37.

[17] Kumamoto S., Takahashi Y., Ishibashi K., Noda Y., Yamada K. and Chida T., Transmater Res. Soc. Jpn, 18A, 647 (1994).
[18] Mutasim H. Elhussien, Yusuf M Isa.,Tea bags derived activated carbon for the removal of $\mathrm{As}$ (III) and $\mathrm{Pb}$ (II), International Journal of Sudan Research, accepted for publication.

[19] Mutasim H. Elhussien, Yusuf M Isa., (2015), Evaluation of the Adsorption Capacities of Activated Charcoal from Sudanese Wooden Parts of Prosopis juliflora, Acacia Nilotica, and Rhamnus Frangula, International Journal of Emerging Technology and Advanced Engineering, 5(4): 582-587.

[20] Tang, C., Zhang, R., Wen, S., Li, K., Zheng, X., Zhu, M. Adsorption of hexavalent chromium from aqueous solution on raw and modified activated carbon. Water Environment research, 81 (7), 2009, 728-734.

[21] Barkat, M., Nibou, D., Chegrouche, S., Mellah, A. Kinetics and thermodynamics studies of chromium (VI) ions adsorption onto activated carbon from aqueous solutions. Chemical Engineering and Processing: Process Intensification, 48 (1), 2009, 38-47.

[22] Ahmadpour, A., Do, D. The preparation of activated carbon from macadamia nutshell by chemical activation. Carbon, 35, 1997, 1723-1732.

[23] Helfferich., F. Ion exchange. New York: McGraw-Hill; 1962.

[24] Sudaryanto Y., Hartono S.B., Irawaty W., H. Hindarso, Ismadji S., High surface area activated carbon prepared from cassava peel by chemical activation, Bioresource Technology 97, 734 739 (2006).

[25] Hayashi J., Kazehaya A., Muroyama K., Watkinson A. P., Preparation of activated carbon from lignin by chemical activation, Carbon 38, 1873-1878 (2000).

[26] Namasivayam. C. Kadirvelu, K., Activated carbon from coirpith by physical and chemical activation methods. Bioresour. Technol. 62, 123-127(1997).

[27] T. A. Maranhao, D. L. G. Borges, M. A. M. S. da Veiga, A. J. Curtius, Cloud point extraction for the determination of cadmium and lead in biological samples by graphite furnace atomic absorption spectrometry, Spectrochim. Acta 60 (2005) 667.

[28] Mutasim H. Elhussien, Yusuf M Isa.,2015- Langmuir, Freundlich Adsorption Isotherms and Kinetics for the Removal of Methylene Blue Dye from Aqueous Solution using Activated Carbon Derived from Pods of Acacia nilotica var astringens (Sunt tree) by Chemical Activation with $\mathrm{ZnCl}_{2}$, Chemical Process and Engineering Research, vol.(38): 25-34.

[29] Dubinin, M. M., Radushkevich, L. V. The equation of the characteristic curve of activated charcoal, Doklady Akademii Nauk SSSR, 55, 1947, 327-329.

[30] Choy, K. K. H., Porter, J. F., McKay, G. Langmuir isotherm models applied to the multi component sorption of acid dyes from effluent onto activated carbon, Chemical Engineering Journal, 45, 2000, 575-584.

[31] Igwe, J. C., Abia, A. A. Equilibrium sorption isotherm studies of $\mathrm{Cd}$ (II), $\mathrm{Pb}$ (II) and $\mathrm{Zn}$ (II) ions detoxification from waste water using unmodified and EDTA-modified maize husk. Electronic Journal of Biotechnology, 10 (4), 2007, 536-548.

[32] Maji, S. K., Pal, A., Pal, T., Adak, A. Adsorption thermodynamics of arsenic on Laterite soil. Journal of Surface Science and Technology, 2007, 22 (3-4), 161-176. 
[33] Helfferich., F. Ion exchange. New York: McGraw-Hill; 1962.

[34] Swami., N, Dreisinger., D. B. Kinetics of zinc removal from cobalt electrolytes by ion exchange. Solvent Extraction and Ion Exchange, 13, 1995, 1037-1062.
[35] Horshall, M. Jnr., Spiff, A. I., Abia, A. A. Studies on the influence of mercaptoacetic acid (MAA) modification of cassava (Manihot sculenta Cranz) waste biomass on the adsorption of $\mathrm{Cu}^{2+}$ and $\mathrm{Cd}^{2+}$ from aqueous solution. Bulletin of Korean Chemical Society, 25 (7), 2004, 969- 976. 